\title{
Synthesis and thermal behavior of triblock semifluorinated n-alkanes
}

\author{
Anna Chachaj-Brekiesz ${ }^{1}$ - Natalia Górska ${ }^{1}$ Natalia Osiecka ${ }^{2}$. \\ Edward Mikuli ${ }^{1} \cdot$ Patrycja Dynarowicz-Lątka ${ }^{1}$
}

Received: 18 August 2015/Accepted: 2 November 2015/Published online: 20 November 2015

(c) The Author(s) 2015. This article is published with open access at Springerlink.com

\begin{abstract}
A series of semifluorinated long-chain triblock alkanes of the general formula: $\mathrm{H}\left(\mathrm{CH}_{2}\right)_{\mathrm{n}}\left(\mathrm{CF}_{2}\right)_{6}\left(\mathrm{CH}_{2}\right)_{\mathrm{n}} \mathrm{H}$, abbreviated as $\mathrm{H}_{\mathrm{n}} \mathrm{F}_{6} \mathrm{H}_{\mathrm{n}}$, where $n=12,14,16,18$ and 20 , have been synthesized in two steps, by radical addition of

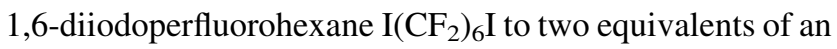
appropriate terminal alkene $\mathrm{CH}_{2}=\mathrm{CH}\left(\mathrm{CH}_{2}\right)_{\mathrm{n}-2} \mathrm{H}$, followed by subsequent deiodination. This novel class of molecules has been subjected for the first time for thermal characterization. Although the structure of these compounds differs from that typical for liquid crystals, the investigated herein (alkyl)-fluoroalkyl-(alkyl) triblocks were found to exhibit thermotropic liquid crystalline phases. Phase polymorphism of the synthesized compounds was investigated upon both heating and cooling, in the temperature range of 270-360 K, using differential scanning calorimetry (DSC). Additionally, polarized optical microscopy was applied in order to identify the phases and characterize the phase transitions on the base of their textures. In the investigated temperature range, the measured compounds exhibit rich phase polymorphism, including different types of liquid crystalline phases (e.g., smectic A, smectic B and smectic E). Upon analyzing DSC results, it can be concluded that for compounds with $n=16,18$ and 20 all the detected phase transitions (crystalline $\leftrightarrow$ smectic, between smectic phases, smectic $\leftrightarrow$ isotropic) shift toward higher temperature with increasing in the hydrocarbon chain length. The phase
\end{abstract}

Patrycja Dynarowicz-Łątka

ucdynaro@cyf-kr.edu.pl

1 Faculty of Chemistry, Jagiellonian University, Ingardena 3, 30-060 Kraków, Poland

2 The Henryk Niewodniczański Institute of Nuclear Physics, Polish Academy of Sciences, Radzikowskiego 152, 31-342 Kraków, Poland situation for compounds with $n=12$ and 14 is slightly different. However, for all the studied compounds, it can be observed that the longer hydrocarbon chain, the higher temperature of the phase transition to the isotropic phase. No metastable phases were observed.

Keywords Triblock semifluorinated alkanes - Liquid crystals - Thermal behavior - Phase transitions - DSC

\section{Introduction}

It is well known that hydrocarbon and fluorocarbon chains have a tendency to demix: Binary mixtures of alkanes and perfluoroalkanes are highly non-ideal, showing large range of liquid-liquid immiscibility as reported already in 1948 by Scott [1]. Such an incompatibility between fluorinated and hydrogenated segments arises from their different structure and properties [2], governed by distinct properties of fluorine and hydrogen atoms. To summarize, fluorine atoms are larger than hydrogens, which results in a larger cross-sectional area for perfluoroalkyl chains than for alkyl chains ( 28.3 vs. $18.5 \AA^{2} \mathrm{~mol}^{-1}$ ). To minimize steric hindrance, the fluorinated chains adopt helical conformation, which causes enhanced chain stiffness, while alkyl chains are granted conformational freedom. Fluorines are more electronegative than hydrogens and form a dense electron shield around the carbon backbone. They are also less polarizable, which leads to weaker van der Walls interactions between fluorinated chains.

Such an antagonistic nature of fluorinated and hydrogenated moieties is brought together in semifluorinated molecules. The simplest and the earliest studied molecules of this kind are semifluorinated alkanes (SFAs) of the general formula $\mathrm{F}\left(\mathrm{CF}_{2}\right)_{\mathrm{m}}\left(\mathrm{CH}_{2}\right)_{\mathrm{n}} \mathrm{H}$ (abbreviated to $\mathrm{F}_{\mathrm{m}} \mathrm{H}_{\mathrm{n}}$ ) 
[3]. The presence of two opposing segments within one molecule makes semifluorinated alkanes, an intriguing class of compounds, which show a peculiar behavior in bulk phase as well as at interfaces [4, 5]. Highly asymmetric structure of these molecules is responsible for their surface activity in organic solvents (they were called primitive surfactants after Turberg and Brady [6]) and allows for Langmuir monolayer formation at the air/water interface [7], despite the absence of any polar group in their structure

Semifluorinated alkanes led to a breakthrough in understanding not only surface activity of molecules but also their liquid crystalline properties. Mahler et al. [8] originally reported smectic ordering for $\mathrm{F}_{10} \mathrm{H}_{10}$. This finding had a great impact to the field of liquid crystals chemistry as in traditional approach it was commonly believed that smectogenic molecules require rigid, rod-like moiety (represented by aromatic core, build usually from biphenyl ring, or multiple bonds) that is extended by one or two flexible aliphatic chains [9]. Neither completely flexible molecules (which do not have orientational order) nor purely rigid compounds (which transform directly from the isotropic liquid phase at high temperature to the crystalline solid phase at low temperature) were found to form liquid crystalline phases. However, it appears that one of the factors that play an important role in smectic ordering is the amphiphilic character of molecules. The presence of two distinct moieties of limited mutual miscibility within a molecule is responsible for the formation of separate alternating sublayers, and the resulting periodicity gives rise to smectic layering [8]. The formation of smectic phases by SFAs can be explained by the fact that perfluorocarbons and hydrocarbons are mutually immiscible, and a molecule, in which these two segments are covalently bound, exhibits amphiphilic character to an appreciable extent. Smectic ordering was observed only for SFAs having 6-12 carbon atoms in the protonated fragment, while SFAs with either $n \leq 5$ or $n>12$ did not show smectic textures in polarized light $[10,11]$. The length of the perfluorinated fragment is also important as the liquid crystalline properties are concerned since SFA molecules having less than eight carbon atoms in their perfluorinated chain do not form smectic phases [12].

Inspired by such interesting properties of diblock semifluorinated alkanes, we have synthesized (alkyl)Falkyl(alkyl) triblock molecules of the general formula: $\mathrm{H}\left(\mathrm{CH}_{2}\right)_{n}\left(\mathrm{CF}_{2}\right)_{m}\left(\mathrm{CH}_{2}\right)_{n} \mathrm{H}$ (in short $\left.\mathrm{H}_{n} \mathrm{~F}_{\mathrm{m}} \mathrm{H}_{n}\right)$ with perfluorohexane moieties $\left(\mathrm{F}_{6}\right)$, while the length of the alkyl chain was varied $\left(\mathrm{H}_{7}, \mathrm{H}_{8}, \mathrm{H}_{9}, \mathrm{H}_{11}, \mathrm{H}_{12}, \mathrm{H}_{14}, \mathrm{H}_{16}, \mathrm{H}_{18}, \mathrm{H}_{20}\right)$, and studied their thermal behavior. Although the synthesis procedure of such triblock semifluorinated alkanes has already been reported [5, 13], these substances have not been subjected so far for any thermal characterization experiments. Therefore, the aim of this paper was to fulfill this gap.

Differential scanning calorimetry (DSC) measurements have been taken with different heating/cooling scanning rates in order to check the stability of the studied substances, investigate their thermal behavior, determine phase transition temperatures, and estimate enthalpy and entropy changes at these transitions. In addition, textures of the detected phases were classified with polarizing optical microscope (POM). Our investigations show that compounds having $<12$ carbon atoms in their alkyl moieties show only one transition from solid state to isotropic liquid (IL), while molecules with longer hydrogenated chains exhibit rich phase polymorphism, including different types of liquid crystalline phases. Therefore, in this paper, we focus only on liquid crystalline molecules, i.e., $\mathrm{H}_{12} \mathrm{~F}_{6} \mathrm{H}_{12}$, $\mathrm{H}_{14} \mathrm{~F}_{6} \mathrm{H}_{14}, \mathrm{H}_{16} \mathrm{~F}_{6} \mathrm{H}_{16}, \mathrm{H}_{18} \mathrm{~F}_{6} \mathrm{H}_{18}$ and $\mathrm{H}_{20} \mathrm{~F}_{6} \mathrm{H}_{20}$.

\section{Experimental}

\section{Synthesis}

Semifluorinated triblock molecules $\left(\mathrm{H}_{\mathrm{n}} \mathrm{F}_{\mathrm{m}} \mathrm{H}_{\mathrm{n}}\right)$ were synthesized by two-step procedure, involving radical addition of 1,6-diiodoperfluorohexane to two equivalents of an appropriate terminal alkene, followed by deiodination of the resulting diiodinated intermediate. Although a scheme of this synthesis has already been described [5, 13], to the best of our knowledge, full description of the reaction conditions and physicochemical properties of (alkyl)Falkyl(alkyl) triblock molecules has not been published so far. Therefore, exemplary experimental procedure for synthesis of $\mathrm{H}_{20} \mathrm{~F}_{6} \mathrm{H}_{20}$ and the characteristics of all the obtained triblock molecules have been provided below.

\section{1,21,22,22,23,23,24,24,25,25,26,26-dodecafluoro-19,28- diiodo-hexatetracontane $\left(\mathrm{H}_{20} \mathrm{~F}_{6} \mathrm{H}_{20} \mathrm{I}_{2}\right)$}

1,6-diiodoperfluorohexane (1.00 g, $1.80 \mathrm{mmol})$, eicos-1ene $(1,01 \mathrm{~g}, 3.60 \mathrm{mmol})$ and 2,2'-azobis(2-methylpropionitrile) $(15 \mathrm{mg}, 5 \% \mathrm{~mol})$ were stirred under nitrogen for $5 \mathrm{~h}$ at temperature $90{ }^{\circ} \mathrm{C}$. Crude diiodide was obtained after purification by column chromatography (silica gel/ hexanes) in $82 \%$ yield. ${ }^{1} \mathrm{H} \mathrm{NMR}\left(300 \mathrm{MHz}, \mathrm{CDCl}_{3}\right) \delta$ 4.39-4.28 (m, 1H), 3.06-2.64 (m, 2H), 1.91-1.70 (m, 2H), $1.43-1.20(\mathrm{~m}, 34 \mathrm{H}), 0.92-0.84(\mathrm{~m}, 3 \mathrm{H})$.

$21,21,22,22,23,23,24,24,25,25,26,26-$ dodecafluorohexatetracontane $\left(\mathrm{H}_{20} \mathrm{~F}_{6} \mathrm{H}_{20}\right)$

Solution of $\mathrm{H}_{20} \mathrm{~F}_{6} \mathrm{H}_{20} \mathrm{I}_{2}$ (1.60 g, $\left.1.44 \mathrm{mmol}\right)$ in tetrahydrofurane $\left(3 \mathrm{~cm}^{3}\right)$ and zinc powder $(0.37 \mathrm{~g}, 5.76 \mathrm{mmol})$ were 
sequentially added to glacial acetic acid $\left(6 \mathrm{~cm}^{3}\right)$. Resulting slurry was stirred overnight under nitrogen atmosphere at temperature $50{ }^{\circ} \mathrm{C}$. Then, water $\left(10 \mathrm{~cm}^{3}\right)$ was added, and aqueous phase was extracted with chloroform $\left(3 \times 10 \mathrm{~cm}^{3}\right)$. Organic extracts were combined, washed with water $\left(10 \mathrm{~cm}^{3}\right)$, brine $\left(10 \mathrm{~cm}^{3}\right)$, dried over anhydrous magnesium sulfate and concentrated under vacuum. The oily residue was purified by column chromatography (silica gel/hexanes) followed by crystallization from methanol. $\mathrm{H}_{20} \mathrm{~F}_{-} \mathrm{H}_{20}$ was obtained in $76 \%$ yield as white, fine crystals: ${ }^{1} \mathrm{H}$ NMR $\left(300 \mathrm{MHz}, \mathrm{CDCl}_{3}\right) \delta 2.15-1.94(\mathrm{~m}, 4 \mathrm{H}), 1.68-1.52(\mathrm{~m}, 4 \mathrm{H})$, $1.34-1.24(\mathrm{~m}, 68 \mathrm{H}), 0.88(t, J=6.7 \mathrm{~Hz}, 6 \mathrm{H})$; elemental composition measured: $64.33 \% \mathrm{C}, 9.38 \% \mathrm{H}$ (calculated: $64.01 \% \mathrm{C}, 9.58 \% \mathrm{H}, 26.41 \% \mathrm{~F})$.

Other compounds were obtained following this experimental procedure:

$19,19,20,20,21,21,22,22,23,23,24,24-$

dodecafluorodotetracontane $\left(\mathrm{H}_{18} \mathrm{~F}_{6} \mathrm{H}_{18}\right)$

${ }^{1} \mathrm{H}$ NMR $\left(300 \mathrm{MHz}, \mathrm{CDCl}_{3}\right) \delta$ 2.11-1.98 (m, 4H), $1.63-1.55(\mathrm{~m}, 4 \mathrm{H}), 1.41-1.23 \quad(\mathrm{~m}, 60 \mathrm{H}), 0.88 \quad(t$, $J=7.0 \mathrm{~Hz}, 6 \mathrm{H})$; elemental composition measured: $62.46 \% \mathrm{C}, 9.36 \% \mathrm{H}$ (calculated: $62.51 \% \mathrm{C}, 9.24 \% \mathrm{H}$, $28.25 \%$ F). $17,17,18,18,19,19,20,20,21,21,22,22$-dodecafluorooctatriacontane $\left(\mathrm{H}_{16} \mathrm{~F}_{-6} \mathrm{H}_{16}\right)$ : ${ }^{1} \mathrm{H}$ NMR $(300 \mathrm{MHz}$, $\left.\mathrm{CDCl}_{3}\right) \delta 2.10-1.98(\mathrm{~m}, 4 \mathrm{H}), 1.64-1.55(\mathrm{~m}, 4 \mathrm{H}), 1.41-$ $1.22(\mathrm{~m}, 52 \mathrm{H}), 0.88(\mathrm{t}, J=7.0 \mathrm{~Hz}, 6 \mathrm{H})$; elemental composition measured: $61.18 \% \mathrm{C}, 8.68 \% \mathrm{H}$ (calculated: $60.78 \% \mathrm{C}, 8.86 \% \mathrm{H}, 30.36 \% \mathrm{~F})$.

\section{$15,15,16,16,17,17,18,18,19,19,20,20$ - \\ dodecafluorotetratriacontane $\left(\mathrm{H}_{14} \mathrm{~F}_{6} \mathrm{H}_{14}\right)$}

${ }^{1} \mathrm{H}$ NMR $\left(300 \mathrm{MHz}, \mathrm{CDCl}_{3}\right) \delta 2.15-1.94(\mathrm{~m}, 4 \mathrm{H}), 1.67-1.53$ $(\mathrm{m}, 4 \mathrm{H}), 1.44-1.20(\mathrm{~m}, 44 \mathrm{H}), 0.88(t, J=6.7 \mathrm{~Hz}, 6 \mathrm{H})$; elemental composition measured: $58.47 \% \mathrm{C}, 8.05 \% \mathrm{H}$ (calculated: $58.77 \% \mathrm{C}, 8.41 \% \mathrm{H}, 32.81 \% \mathrm{~F}$ ).

$13,13,14,14,15,15,16,16,17,17,18,18$

dodecafluorotriacontane $\left(\mathrm{H}_{12} \mathrm{~F}_{6} \mathrm{H}_{12}\right)$

${ }^{1} \mathrm{H} N M R\left(300 \mathrm{MHz}, \mathrm{CDCl}_{3}\right) \delta 2.16-1.93(\mathrm{~m}, 4 \mathrm{H}), 1.67-1.52$ $(\mathrm{m}, 4 \mathrm{H}), 1.44-1.20(\mathrm{~m}, 36 \mathrm{H}), 0.88(t, J=6.7 \mathrm{~Hz}, 6 \mathrm{H})$; elemental composition measured: $56.79 \% \mathrm{C}, 7.84 \% \mathrm{H}$ (calculated: $56.41 \%$ C, $7.89 \%$ H, $35.69 \% \mathrm{~F}$ ).

\section{Thermal analysis}

\section{Differential scanning calorimetry}

DSC measurements were taken for the perfluorinated series of triblock of the $\mathrm{H}\left(\mathrm{CH}_{2}\right)_{\mathrm{n}}\left(\mathrm{CF}_{2}\right)_{6}\left(\mathrm{CH}_{2}\right)_{n} \mathrm{H}$ general formula (hereafter referred to as $\mathrm{H}_{\mathrm{n}} \mathrm{F}_{6} \mathrm{H}_{\mathrm{n}}$ ) using a Mettler-Toledo $822^{\mathrm{e}}$ instrument in the temperature range of $230-360 \mathrm{~K}$. The measurements were taken for the bulk samples with $n=12,14,16,18$ and 20 of masses equal to $4.85,7.01$, $1.90,5.36$ and $2.90 \mathrm{mg}$, respectively, with the scanning rates of 10,5 and $2 \mathrm{~K} \mathrm{~min}^{-1}$. The samples were placed in hermetically sealed aluminum pans $(30 \mu \mathrm{L})$. The instrument was calibrated using the literature data for indium and water melting points. The enthalpy changes $(\Delta H)$ linked up with observed transitions were calculated by numerical integration of the DSC curves under the peaks of the anomalies. Both, $T_{\text {onset }}$ and $T_{\text {peak }}$, were calculated for every anomaly observed in the DSC curves on heating and cooling. The estimations of entropy changes $(\Delta S)$ were calculated using the following formula: $\Delta S=\Delta H / T_{\text {peak }}$ [14]. The transition temperatures are given with accuracy of $\pm 0.5 \mathrm{~K}$. Standard deviations of the values of the enthalpy and entropy changes at the transitions are given in Table 1.

\section{Polarized optical microscope}

Liquid crystal textures of mesophases were investigated using Biolar PI polarized microscope (PZO Warsaw). The temperature was stabilized by Linkam THM 600 silver heating/cooling stage and TMS 90 temperature controller. Substances were placed between two glass plates at the temperature above melting point. Thickness of samples was measured by platinum resistance thermometer stabilized with temperature accuracy of $\pm 0.1 \mathrm{~K}$. The observation was carried out during heating and cooling with temperature rates of $0.5-50 \mathrm{~K} \mathrm{~min}^{-1}$, and in the temperature range of $173-423 \mathrm{~K}$.

\section{Results and discussion}

Figure 1 presents the DSC curves for $\mathrm{H}_{12} \mathrm{~F}_{6} \mathrm{H}_{12}$ registered in the temperature range of $240-340 \mathrm{~K}$ during heating (upper red curve) and subsequent cooling (lower blue curve) as well as phase identification from texture observation (Fig. 2).

The $\mathrm{H}_{12} \mathrm{~F}_{6} \mathrm{H}_{12}$ homolog has six different phases, which can be distinguished in the DSC curve. Polarized microscope observation of the steadily cooled sample complemented with DSC curves led to the following phase sequence:

Iso $\stackrel{331 K}{\longrightarrow} \mathrm{SmB} \stackrel{330 K}{\longrightarrow} \mathrm{SmE} \stackrel{316 K}{\longrightarrow} \mathrm{Cr} \stackrel{296 K}{\longrightarrow} \mathrm{Cr} /$ Glass $\stackrel{250 K}{\longrightarrow}$ Glass

During cooling of the $\mathrm{H}_{12} \mathrm{~F}_{6} \mathrm{H}_{12}$ sample from $360 \mathrm{~K}$ down, cracking of the texture was visible from about $310-250 \mathrm{~K}$, suggesting partial vitrification process [15]. 


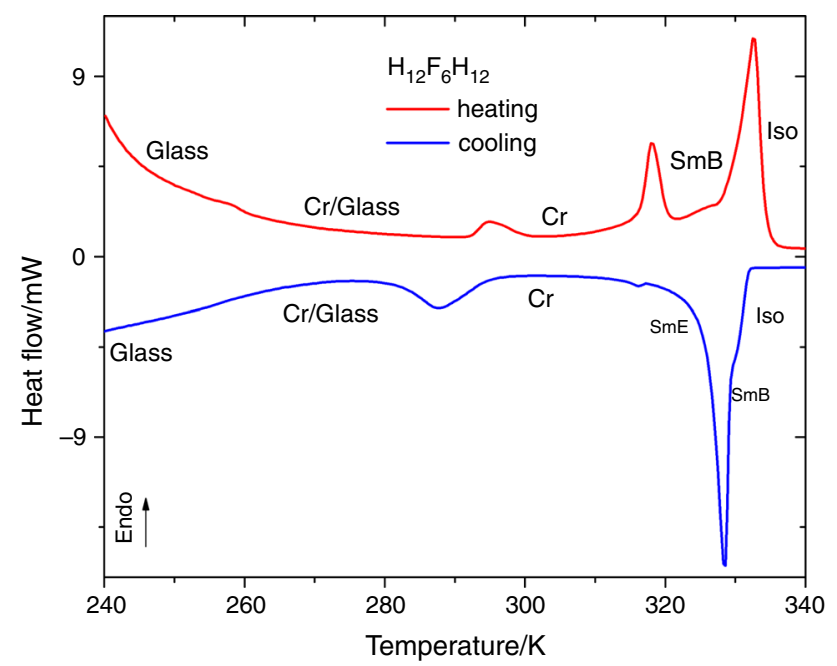

Fig. 1 DSC curves of $\mathrm{H}_{12} \mathrm{~F}_{6} \mathrm{H}_{12}$ registered during heating and subsequent cooling with a scanning rate of $10 \mathrm{~K} \mathrm{~min}^{-1}$

From texture observation, it is clear that one crystalline phase exists between 300 and $316 \mathrm{~K}$ and this phase is rather plastic than liquid. During heating, conversion of the vitreous phase into crystalline phase was observed at about $300 \mathrm{~K}$. The transition between smectic E and the crystalline phase ( $\mathrm{SmE} \leftrightarrow \mathrm{Cr}$ ) was visible in the DSC curve at about $316 \mathrm{~K}$ only upon cooling and applying faster scanning rate than $2 \mathrm{~K} \mathrm{~min}^{-1}\left(5\right.$ or $\left.10 \mathrm{~K} \mathrm{~min}^{-1}\right)$.

The calorimetric results for the $\mathrm{H}_{14} \mathrm{~F}_{6} \mathrm{H}_{14}$ sample registered between 227 and $350 \mathrm{~K}$ are shown in Fig. 3. From texture observation (Fig. 4) complemented with DSC experiment, the following phase sequence can be determined:

Iso $\stackrel{338 K}{\longrightarrow} \mathrm{SmA} \stackrel{329 K}{\longrightarrow} \mathrm{SmB} \stackrel{324 K}{\longrightarrow} \mathrm{SmE} \stackrel{317 K}{\longrightarrow} \mathrm{Cr} \stackrel{298 K}{\longrightarrow} \mathrm{Cr} /$ Glass $\stackrel{235 K}{\longrightarrow}$ Glass

The $\mathrm{H}_{14} \mathrm{~F}_{6} \mathrm{H}_{14}$ homolog has seven different phases, and its polymorphism is the richest among the five homologs investigated herein. This is the only compound where the transition between smectic A and smectic B phases $(\mathrm{SmA} \leftrightarrow \mathrm{SmB})$ can be noticed in the DSC curves but only

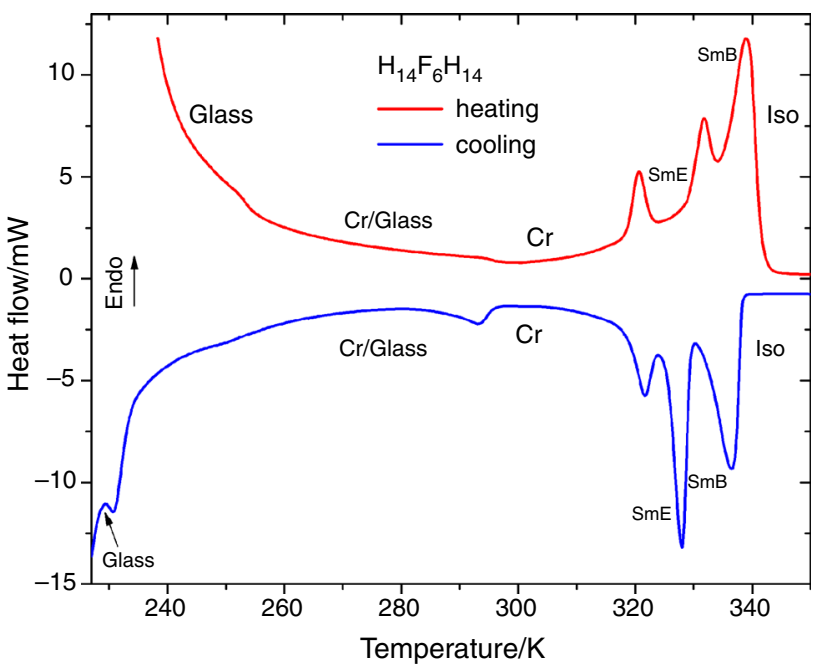

Fig. 3 DSC curves of $\mathrm{H}_{14} \mathrm{~F}_{6} \mathrm{H}_{14}$ registered during heating and subsequent cooling with a scanning rate of $10 \mathrm{~K} \mathrm{~min}^{-1}$

applying scanning rates of 5 or $2 \mathrm{~K} \mathrm{~min}^{-1}$. Focal conic textures of $\mathrm{SmA}$ and $\mathrm{SmB}$ phases are similar to each other (Fig. 4a, b). At the temperature of the SmA $\rightarrow$ SmB phase transition, the so-called transition bars were observed, which are characteristic for the appearance of $\mathrm{SmB}$ phase [16]. The existence of vitreous phases, similar to $\mathrm{H}_{12} \mathrm{~F}_{6} \mathrm{H}_{12}$, was also confirmed by texture observation. The crack formation was visible during cooling of the sample at about $305 \mathrm{~K}$, and disappearance of these cracks was visible during subsequent heating at about $307 \mathrm{~K}$.

The phase situation observed between 245 and $355 \mathrm{~K}$ for a higher homolog, i.e., $\mathrm{H}_{16} \mathrm{~F}_{6} \mathrm{H}_{16}$, is seen in Fig. 5.

In the investigated temperature range, five different phases are seen for $\mathrm{H}_{16} \mathrm{~F}_{6} \mathrm{H}_{16}$ (Fig. 6):

Iso $\stackrel{337 K}{\longrightarrow} \mathrm{SmB} \stackrel{333 K}{\longrightarrow} \mathrm{SmE} \stackrel{318 K}{\longrightarrow} \mathrm{CrI} \stackrel{272 K}{\longrightarrow} \mathrm{CrII}$

Contrary to the previously discussed compound, no vitreous phases were observed. In turn, one phase transition at $T_{\mathrm{C}}=278$ and $272 \mathrm{~K}$ between two crystalline phases (CrII $\leftrightarrow \mathrm{CrI}$ ) was registered on DSC curve during heating (a)

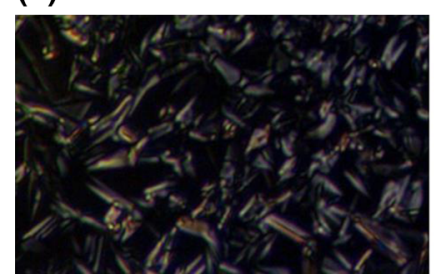

(b)

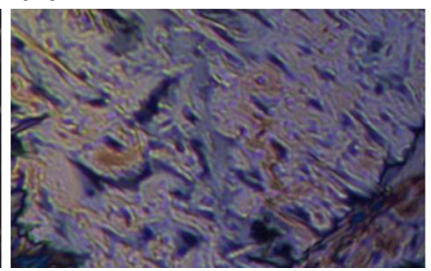

(c)

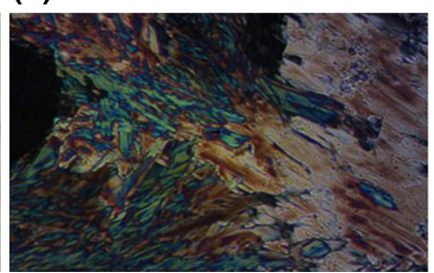

(d)

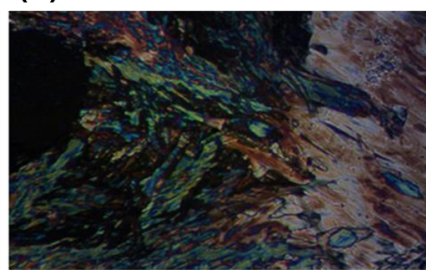

Fig. 2 Textures of $\mathrm{H}_{12} \mathrm{~F}_{6} \mathrm{H}_{12}$ compound: a SmB phase $(T=331 \mathrm{~K})$, b SmE phase $(T=318 \mathrm{~K})$, c crystal phase $(T=306 \mathrm{~K})$ and $\mathbf{d}$ glass phase $(256 \mathrm{~K})$ observed upon cooling with the rate of $10 \mathrm{~K} \mathrm{~min}^{-1}$ 
(a)

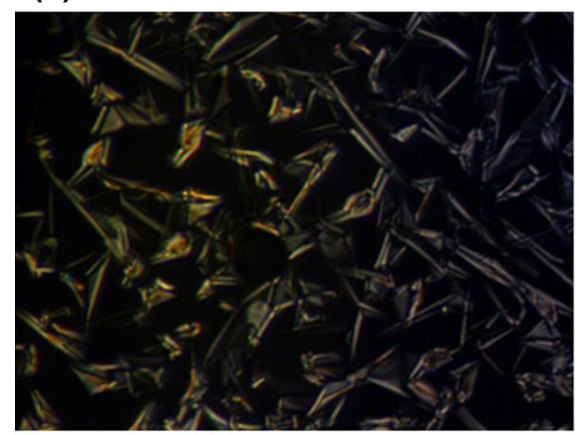

(d)

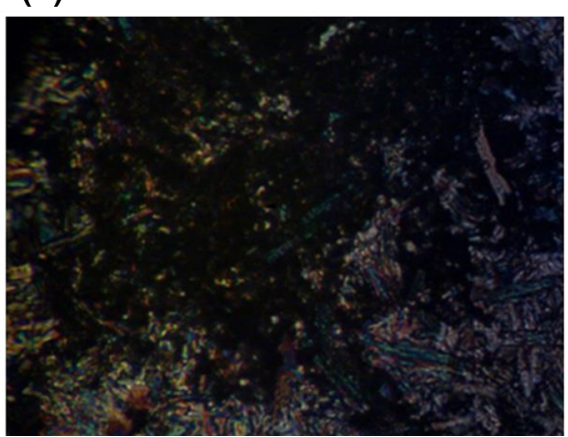

(b)

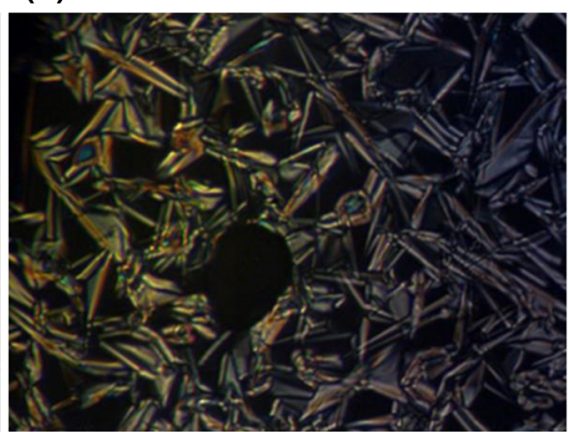

(e)

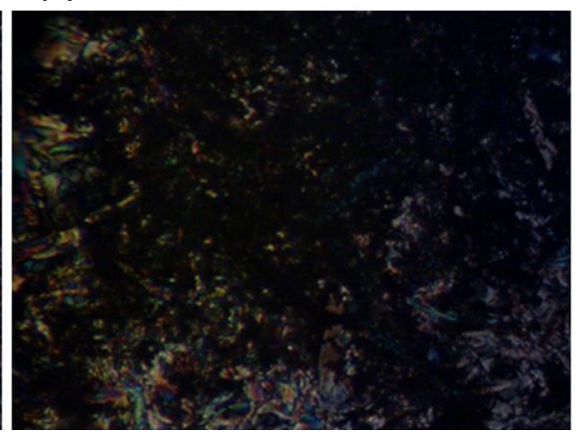

Fig. 4 Textures of for $\mathrm{H}_{14} \mathrm{~F}_{6} \mathrm{H}_{14}$ compound a SmA phase $(T=341 \mathrm{~K})$, b SmB phase $(T=338 \mathrm{~K})$, c SmE phase $(T=325 \mathrm{~K})$, d crystal phase $(T=307 \mathrm{~K})$ and e glass phase $(T=221 \mathrm{~K})$ observed upon cooling with the rate of $10 \mathrm{~K} \mathrm{~min}-1$

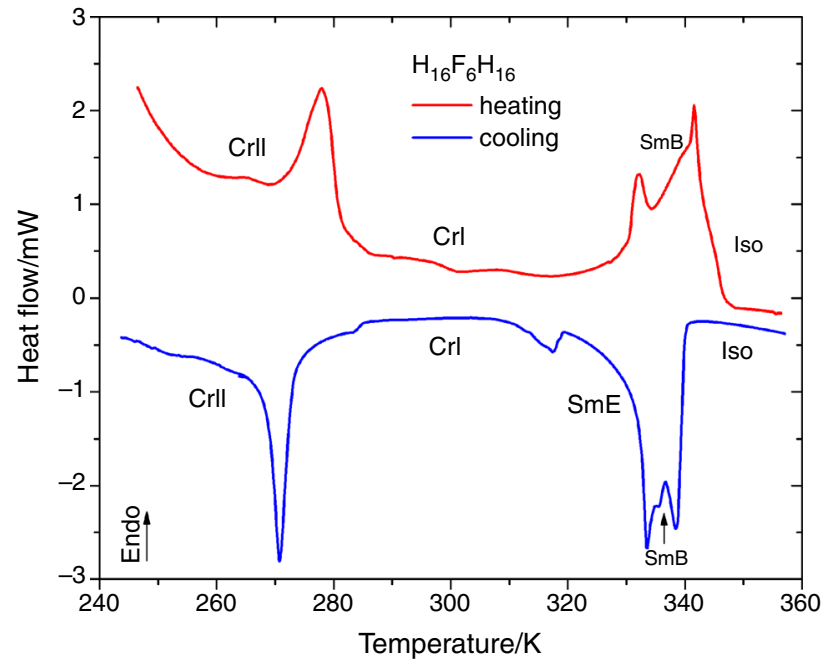

Fig. 5 DSC curves of $\mathrm{H}_{16} \mathrm{~F}_{6} \mathrm{H}_{16}$ registered during heating and subsequent cooling with a scanning rate of $10 \mathrm{~K} \mathrm{~min}^{-1}$

and cooling, respectively. The transition between smectic $\mathrm{E}$ and the crystalline phase at about $318 \mathrm{~K}$ ( $\mathrm{SmE} \leftrightarrow \mathrm{CrI})$ was visible in the DSC curve only during cooling procedure.

In Fig. 7, the DSC measurements for the $\mathrm{H}_{18} \mathrm{~F}_{6} \mathrm{H}_{18}$ performed in the temperature range of $260-360 \mathrm{~K}$ are (c)

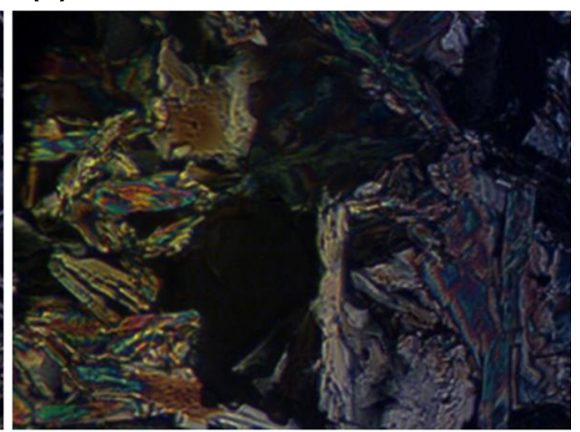


(a)

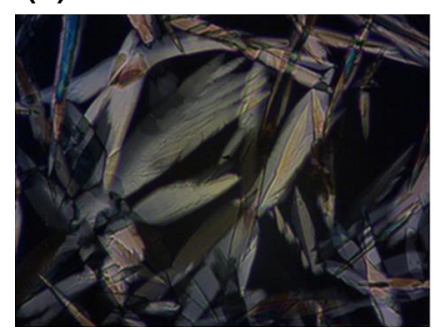

(b)

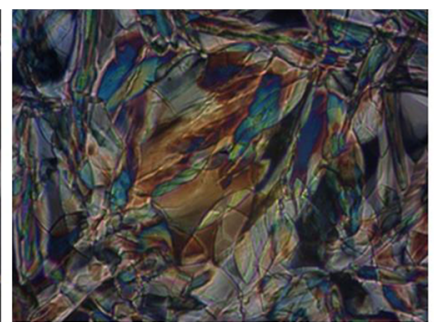

(c)

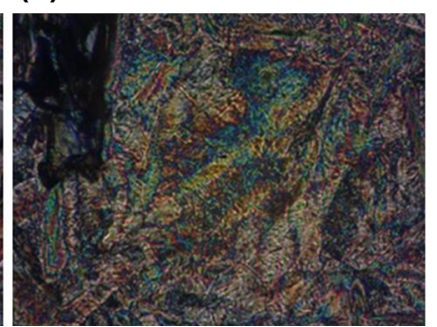

(d)

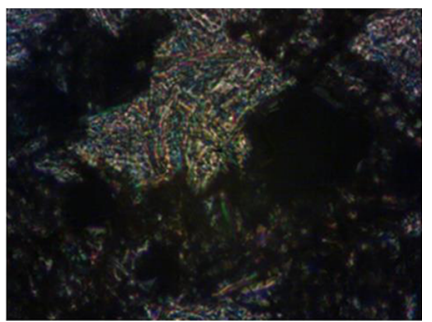

Fig. 6 Textures of $\mathrm{H}_{16} \mathrm{~F}_{6} \mathrm{H}_{16}$ compound a SmB phase $(T=335 \mathrm{~K})$, b SmE phase $(T=320 \mathrm{~K})$, c crystal I phase $(T=286 \mathrm{~K})$ and $\mathbf{d}$ crystal II phase $(T=245 \mathrm{~K})$ observed upon cooling with the rate of $10 \mathrm{~K} \mathrm{~min}^{-1}$

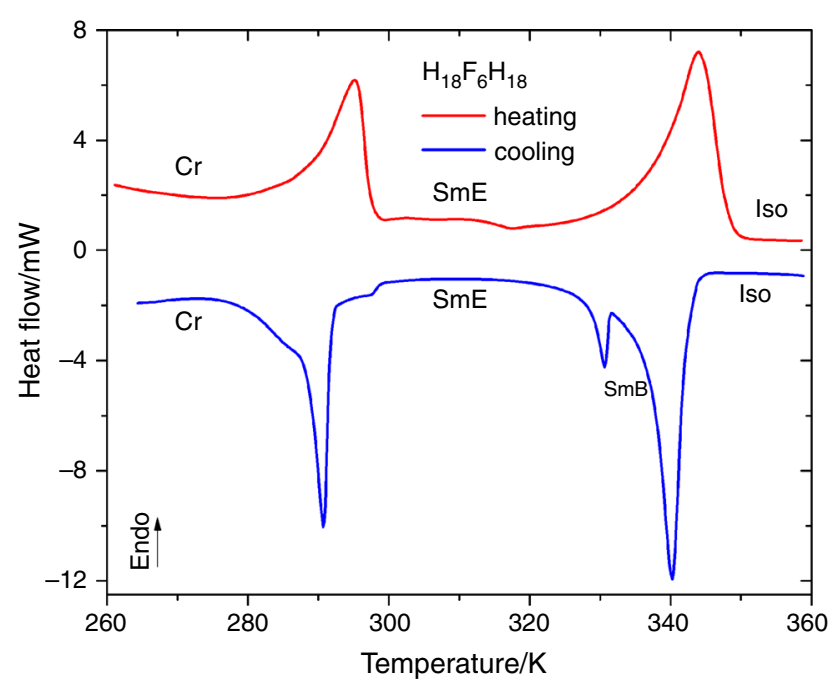

Fig. 7 DSC curves of $\mathrm{H}_{18} \mathrm{~F}_{6} \mathrm{H}_{18}$ registered during heating and subsequent cooling with a scanning rate of $10 \mathrm{~K} \mathrm{~min}^{-1}$

The thermodynamic parameters of the detected phase transitions, based on the DSC results, are shown in Table 1, while Table 2 compiles transition temperatures observed with polarizing microscope. In all the investigated sub-

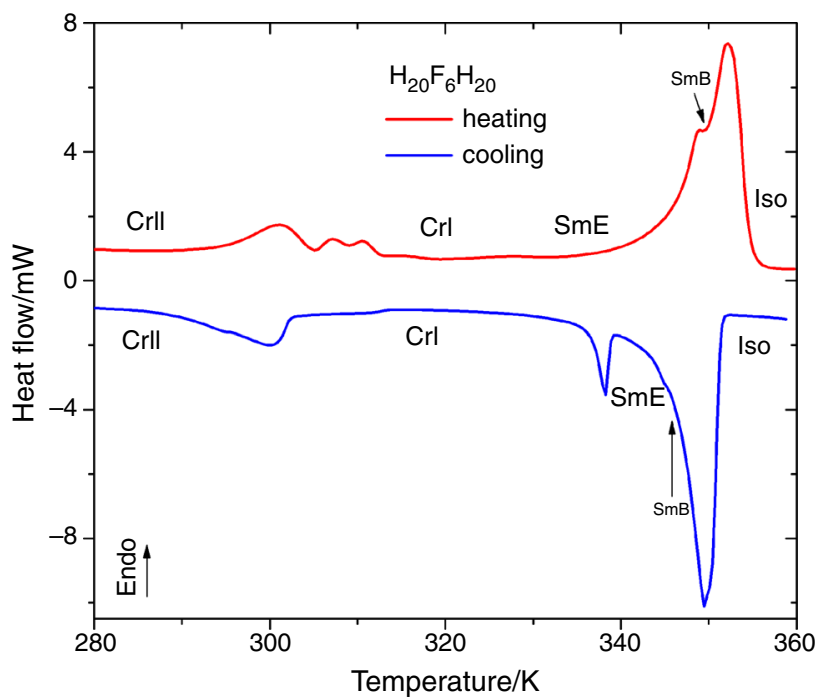

Fig. 9 DSC curves of $\mathrm{H}_{20} \mathrm{~F}_{6} \mathrm{H}_{20}$ registered during heating and subsequent cooling with a scanning rate of $10 \mathrm{~K} \mathrm{~min}^{-1}$

stances, thermotropic liquid crystalline phases, smectic B and smectic E, were found. Also, a general tendency was noticed, i.e., the phase transition temperatures between smectic $\mathrm{E}$ and smectic $\mathrm{B}$ phases $(\mathrm{SmE} \leftrightarrow \mathrm{SmB})$, and to the (a)

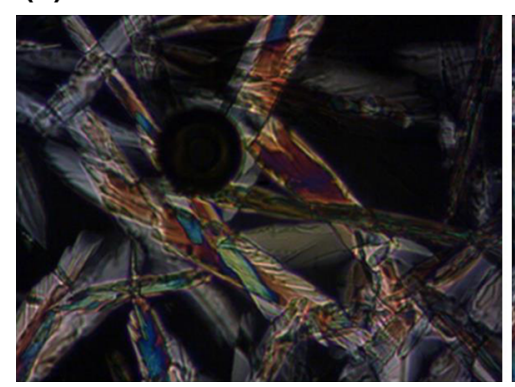

(b)

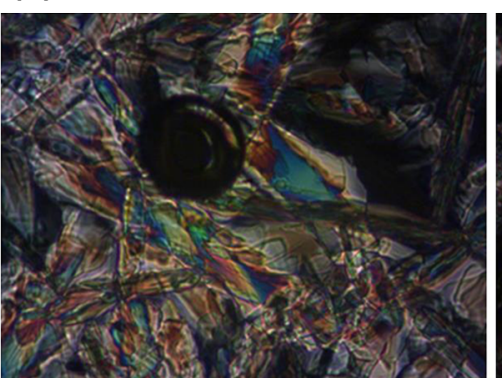

(c)

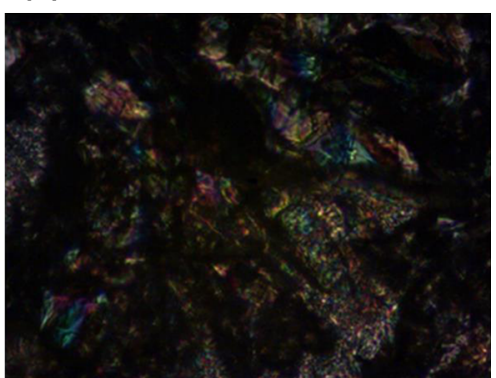

Fig. 8 Textures of $\mathrm{H}_{18} \mathrm{~F}_{6} \mathrm{H}_{18}$ compound: a SmB phase $(T=340 \mathrm{~K})$, b SmE phase $(T=318 \mathrm{~K})$ and $\mathbf{c}$ crystal phase $(T=283 \mathrm{~K})$ observed upon cooling with the rate of $10 \mathrm{~K} \mathrm{~min}^{-1}$ 
(a)

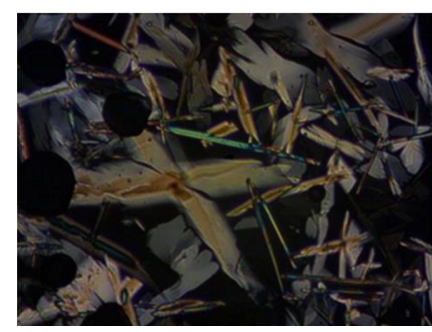

(b)

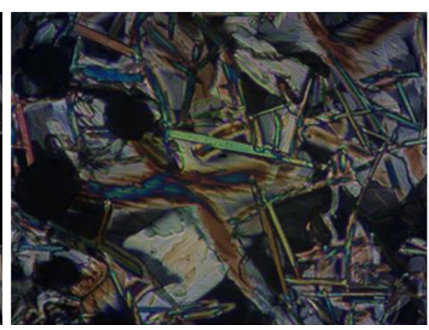

(c)

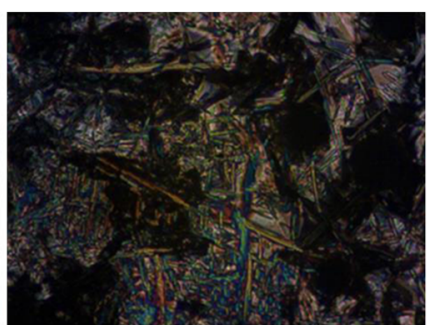

(d)

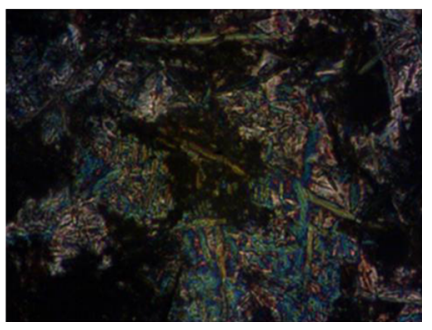

Fig. 10 Textures of $\mathrm{H}_{20} \mathrm{~F}_{6} \mathrm{H}_{20}$ compound: a SmB phase $(T=350 \mathrm{~K})$, b SmE phase $(T=346 \mathrm{~K})$, c crystal I $(T=320 \mathrm{~K})$ and d crystal II $(T=233 \mathrm{~K})$ observed upon cooling with the rate of $10 \mathrm{~K} \mathrm{~min}^{-1}$
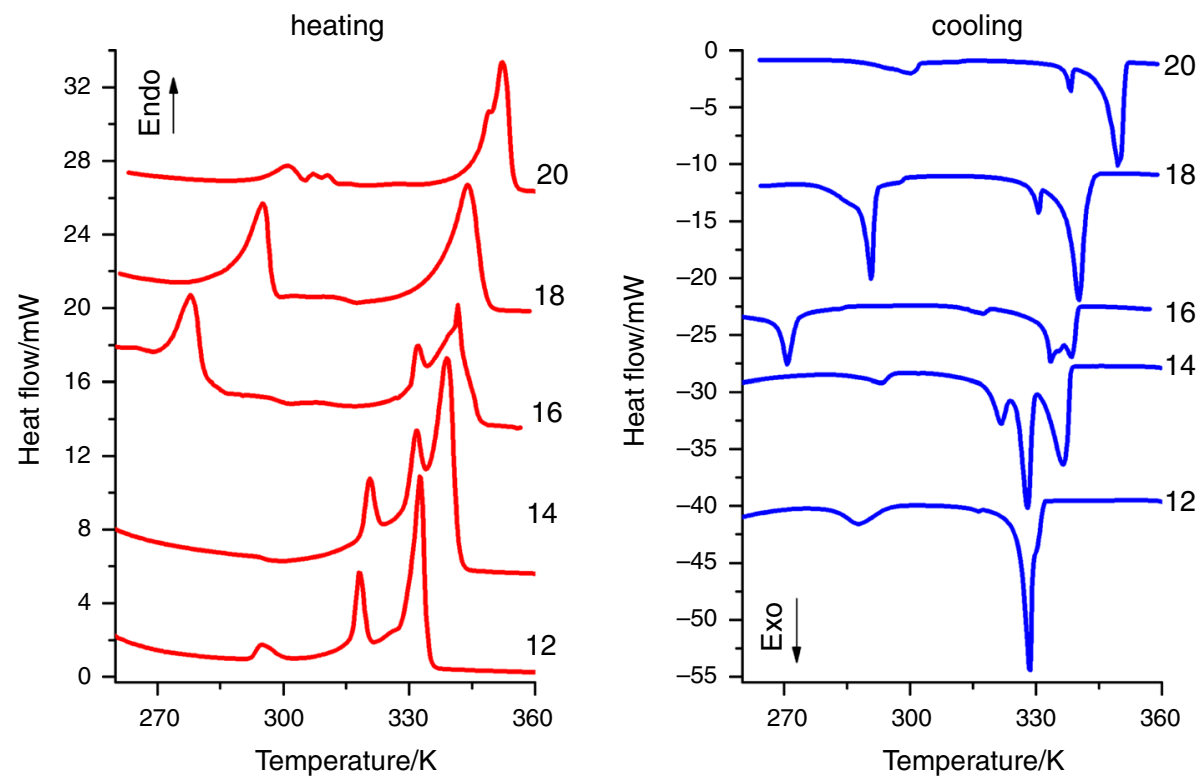

Fig. 11 DSC curves of the $\mathrm{H}_{\mathrm{n}} \mathrm{F}_{6} \mathrm{H}_{\mathrm{n}}(n=12-20)$ samples registered during heating and cooling with a scanning rate of $10 \mathrm{~K}$ min ${ }^{-1}$

Table 1 Thermodynamic parameters of the detected phase transitions for the $\mathrm{H}_{n} \mathrm{~F}_{6} \mathrm{H}_{\mathrm{n}}$ series $(n=12-20)$ by DSC method

\begin{tabular}{|c|c|c|c|c|c|}
\hline Substance & Transition type & $T_{\text {onset }}^{\mathrm{a}} / \mathrm{K}$ & $T_{\text {peak }}^{\mathrm{a}} / \mathrm{K}$ & $\overline{\Delta H} \pm \mathrm{S}_{\Delta H} / \mathrm{kJ} \mathrm{mol}^{-1}$ & $\overline{\Delta S} \pm \mathrm{S}_{\Delta S} / \mathrm{J} \mathrm{mol}^{-1} \mathrm{~K}^{-1}$ \\
\hline \multicolumn{6}{|l|}{ Heating } \\
\hline \multirow[t]{5}{*}{$\mathrm{H}_{12} \mathrm{~F}_{6} \mathrm{H}_{12}$} & Glass $\rightarrow$ Cr/Glass & & $\sim 260$ & $17 \pm 3$ & \\
\hline & $\mathrm{Cr}$ /Glass $\rightarrow \mathrm{Cr}$ & & 300.2 & $39 \pm 5$ & \\
\hline & $\mathrm{Cr} \rightarrow \mathrm{SmE}$ & & & & \\
\hline & $\mathrm{SmE} \rightarrow \mathrm{SmB}$ & 316.0 & 318.1 & & $53 \pm 6$ \\
\hline & $\mathrm{SmB} \rightarrow$ Iso & 327.9 & 332.4 & & $117 \pm 9$ \\
\hline \multirow[t]{6}{*}{$\mathrm{H}_{14} \mathrm{~F}_{6} \mathrm{H}_{14}$} & Glass $\rightarrow \mathrm{Cr}$ /Glass & 239.8 & 250.3 & & \\
\hline & $\mathrm{Cr} /$ Glass $\rightarrow \mathrm{Cr}$ & & $\sim 300$ & & \\
\hline & $\mathrm{Cr} \rightarrow \mathrm{SmE}$ & 313.5 & 314.4 & $4 \pm 1$ & $13 \pm 2$ \\
\hline & $\mathrm{SmE} \rightarrow \mathrm{SmB}$ & 325.5 & 326.7 & $5 \pm 1$ & $15 \pm 2$ \\
\hline & $\mathrm{SmB} \rightarrow \mathrm{SmA}$ & 331.9 & 336.9 & & \\
\hline & $\mathrm{SmA} \rightarrow$ Iso & 336.8 & 338.6 & $30 \pm 5^{b}$ & $89 \pm 8^{c}$ \\
\hline \multirow[t]{4}{*}{$\mathrm{H}_{16} \mathrm{~F}_{6} \mathrm{H}_{16}$} & $\mathrm{CrII} \rightarrow \mathrm{CrI}$ & 270.8 & 278.1 & $21 \pm 3$ & $76 \pm 7$ \\
\hline & $\mathrm{CrI} \rightarrow \mathrm{SmE}$ & & & & \\
\hline & $\mathrm{SmE} \rightarrow \mathrm{SmB}$ & 326.8 & 331.1 & & \\
\hline & $\mathrm{SmB} \rightarrow$ Iso & 331.8 & 339.1 & $53 \pm 5^{\mathrm{b}}$ & $158 \pm 15^{\mathrm{c}}$ \\
\hline
\end{tabular}


Table 1 continued

\begin{tabular}{|c|c|c|c|c|c|}
\hline Substance & Transition type & $T_{\text {onset }}^{\mathrm{a}} / \mathrm{K}$ & $T_{\text {peak }}^{\mathrm{a}} / \mathrm{K}$ & $\overline{\Delta H} \pm \mathrm{S}_{\Delta H} / \mathrm{kJ} \mathrm{mol}^{-1}$ & $\overline{\Delta S} \pm \mathrm{S}_{\Delta S} / \mathrm{J} \mathrm{mol}^{-1} \mathrm{~K}^{-1}$ \\
\hline \multirow[t]{3}{*}{$\mathrm{H}_{18} \mathrm{~F}_{6} \mathrm{H}_{18}$} & $\mathrm{Cr} \rightarrow \mathrm{SmE}$ & 288.0 & 294.7 & $38 \pm 7$ & $129 \pm 12$ \\
\hline & $\mathrm{SmE} \rightarrow \mathrm{SmB}$ & 339.5 & 341.1 & & \\
\hline & $\mathrm{SmB} \rightarrow$ Iso & & 343.8 & $62 \pm 6^{\mathrm{b}}$ & $181 \pm 20^{\mathrm{c}}$ \\
\hline \multirow[t]{4}{*}{$\mathrm{H}_{20} \mathrm{~F}_{6} \mathrm{H}_{20}$} & $\mathrm{CrII} \rightarrow \mathrm{CrI}$ & 295.6 & 302.5 & $19 \pm 1$ & $63 \pm 5$ \\
\hline & $\mathrm{Cr} \rightarrow \mathrm{SmE}$ & & $\sim 327$ & & \\
\hline & $\mathrm{SmE} \rightarrow \mathrm{SmB}$ & 346.6 & 347.4 & & \\
\hline & $\mathrm{SmB} \rightarrow$ Iso & 349.6 & 351.4 & $78 \pm 4^{b}$ & $223 \pm 11^{\mathrm{c}}$ \\
\hline \multicolumn{6}{|l|}{ Cooling } \\
\hline \multirow[t]{5}{*}{$\mathrm{H}_{12} \mathrm{~F}_{6} \mathrm{H}_{12}$} & Iso $\rightarrow \mathrm{SmB}$ & 331.8 & $\sim 330.6$ & $42 \pm 4^{b}$ & $127 \pm 8^{\mathrm{c}}$ \\
\hline & $\mathrm{SmB} \rightarrow \mathrm{SmE}$ & & 329.8 & & \\
\hline & $\mathrm{SmE} \rightarrow \mathrm{Cr}$ & & 316.2 & & \\
\hline & $\mathrm{Cr} \rightarrow \mathrm{Cr} /$ Glass & & 296.0 & & \\
\hline & $\mathrm{Cr} /$ Glass $\rightarrow$ Glass & & $\sim 250$ & & \\
\hline \multirow[t]{6}{*}{$\mathrm{H}_{14} \mathrm{~F}_{6} \mathrm{H}_{14}$} & Iso $\rightarrow \mathrm{SmA}$ & 338.1 & 337.7 & $19 \pm 2$ & $56 \pm 6$ \\
\hline & $\mathrm{SmA} \rightarrow \mathrm{SmB}$ & 330.6 & 329.4 & $14 \pm 2$ & $43 \pm 4$ \\
\hline & $\mathrm{SmB} \rightarrow \mathrm{SmE}$ & 326.0 & 324.2 & $7 \pm 1$ & $22 \pm 3$ \\
\hline & $\mathrm{SmE} \rightarrow \mathrm{Cr}$ & & $\sim 317$ & & \\
\hline & $\mathrm{Cr} \rightarrow \mathrm{Cr} /$ Glass & 299.8 & 297.9 & & \\
\hline & $\mathrm{Cr} /$ Glass $\rightarrow$ Glass & 236.9 & 235.2 & & \\
\hline \multirow[t]{4}{*}{$\mathrm{H}_{16} \mathrm{~F}_{6} \mathrm{H}_{16}$} & Iso $\rightarrow \mathrm{SmB}$ & 338.2 & 337.4 & $46 \pm 1^{b}$ & $137 \pm 10^{\mathrm{c}}$ \\
\hline & $\mathrm{SmB} \rightarrow \mathrm{SmE}$ & & $\sim 333$ & & \\
\hline & $\mathrm{SmE} \rightarrow \mathrm{CrI}$ & 318.7 & 317.6 & $3 \pm 1$ & $9 \pm 1$ \\
\hline & $\mathrm{CrI} \rightarrow \mathrm{CrII}$ & 274.6 & 272.2 & $26 \pm 5$ & $96 \pm 9$ \\
\hline \multirow[t]{3}{*}{$\mathrm{H}_{18} \mathrm{~F}_{6} \mathrm{H}_{18}$} & Iso $\rightarrow \mathrm{SmB}$ & 342.4 & 341.4 & $53 \pm 6$ & $155 \pm 10$ \\
\hline & $\mathrm{SmB} \rightarrow \mathrm{SmE}$ & 332.9 & 332.3 & $4 \pm 1$ & $12 \pm 2$ \\
\hline & $\mathrm{SmE} \rightarrow \mathrm{Cr}$ & 293.0 & 291.9 & $34 \pm 4$ & $116 \pm 7$ \\
\hline \multirow[t]{4}{*}{$\mathrm{H}_{20} \mathrm{~F}_{6} \mathrm{H}_{20}$} & Iso $\rightarrow \mathrm{SmB}$ & 351.2 & 350.8 & $77 \pm 5^{\mathrm{b}}$ & $220 \pm 10^{\mathrm{c}}$ \\
\hline & $\mathrm{SmB} \rightarrow \mathrm{SmE}$ & & 350.1 & & \\
\hline & $\mathrm{SmE} \rightarrow \mathrm{CrI}$ & 339.9 & 339.5 & $5 \pm 1$ & $15 \pm 2$ \\
\hline & $\mathrm{CrI} \rightarrow \mathrm{CrII}$ & 302.6 & 300.7 & $21 \pm 2$ & $70 \pm 6$ \\
\hline
\end{tabular}

a The transition temperatures obtained from anomalies, applying a scanning rate of $2 \mathrm{~K} \mathrm{~min}^{-1}$

b The combined value calculated for both high-temperature anomalies

c The combined value calculated using average $T_{\text {peak }}$ of both high-temperature anomalies

isotropic phase ( $\mathrm{SmB} \leftrightarrow \mathrm{Iso}$ ), increase with increasing length of the hydrocarbon chain. Additionally, smectic A phase was observed for the $\mathrm{H}_{14} \mathrm{~F}_{6} \mathrm{H}_{14}$ homolog. The large value of the entropy change $\left(\Delta S \sim 220 \mathrm{~J} \mathrm{~mol}^{-1} \mathrm{~K}^{-1}\right)$ for the transition between smectic $\mathrm{B}$ and isotropic phases ( $\mathrm{SmB} \leftrightarrow$ Iso) in the $\mathrm{H}_{20} \mathrm{~F}_{6} \mathrm{H}_{20}$ homolog indicates that smectic A phase can also be present in this compound. The transition between two crystalline phases (CrII $\leftrightarrow \mathrm{CrI}$ ) was observed for the $\mathrm{H}_{16} \mathrm{~F}_{6} \mathrm{H}_{16}$ and $\mathrm{H}_{20} \mathrm{~F}_{6} \mathrm{H}_{20}$ homologs. Large values of the entropy change in these transitions $(\Delta S$ between 63 and $96 \mathrm{~J} \mathrm{~mol}^{-1} \mathrm{~K}^{-1}$ ) suggests that they are most probably connected with the conversion to a plastic phase. For the other three compounds, one crystalline phase was observed. Based on texture observation, it is possible to infer they can also be plastic phases. Two compounds, $\mathrm{H}_{12} \mathrm{~F}_{6} \mathrm{H}_{12}$ and $\mathrm{H}_{14} \mathrm{~F}_{6} \mathrm{H}_{14}$, have a tendency to partial converting to vitreous state below $300 \mathrm{~K}$ since cracking of the texture was noticed at this temperature. 
Table 2 Phase transition temperatures observed for the $\mathrm{H}_{n} \mathrm{~F}_{6} \mathrm{H}_{n}$ series $(n=12-20)$ by polarized optical microscopy and description of the discovered phases based on the texture observation

\begin{tabular}{|c|c|c|c|c|}
\hline \multirow[t]{2}{*}{ Substance } & \multicolumn{2}{|l|}{ Cooling } & \multicolumn{2}{|l|}{ Heating } \\
\hline & Phase transition & Temperature/K & Phase transition & Temperature/K \\
\hline \multirow[t]{4}{*}{$\mathrm{H}_{12} \mathrm{~F}_{6} \mathrm{H}_{12}$} & IL-SmB & 332.7 & Disappearance of cracks & 299.81 \\
\hline & SmB-SmE & 330.2 & Isotropization & 336.23 \\
\hline & SmE-Cr & 316.3 & & \\
\hline & Cracking of the texture & 309.9 & & \\
\hline \multirow[t]{5}{*}{$\mathrm{H}_{14} \mathrm{~F}_{6} \mathrm{H}_{14}$} & IL-SmA & 342.5 & Disappearance of cracks & 33.5 \\
\hline & SmA-SmB & 340.9 & $\mathrm{Cr}-\mathrm{SmE}$ & 337.3 \\
\hline & SmB-SmE & 337.9 & SmE-SmB & 346.1 \\
\hline & $\mathrm{SmE}-\mathrm{Cr}$ & 318.4 & Isotropization & 349.3 \\
\hline & Cracking of the texture & 304.9 & & \\
\hline \multirow[t]{4}{*}{$\mathrm{H}_{16} \mathrm{~F}_{6} \mathrm{H}_{16}$} & IL-SmB & 340.5 & CrII-SmE & 277.5 \\
\hline & SmB-SmE & 333.8 & SmE-SmB & 331.1 \\
\hline & SmE-CrI & 312.8 & SmB-IL & 341.3 \\
\hline & $\mathrm{CrI}-\mathrm{CrII}$ & 276.5 & & \\
\hline \multirow[t]{3}{*}{$\mathrm{H}_{18} \mathrm{~F}_{6} \mathrm{H}_{18}$} & IL-SmB & 345.5 & $\mathrm{Cr}-\mathrm{SmE}$ & 294.9 \\
\hline & SmB-SmE & 340.8 & IL-SmB & 348.1 \\
\hline & $\mathrm{SmE}-\mathrm{Cr}$ & 304.8 & & \\
\hline \multirow[t]{4}{*}{$\mathrm{H}_{20} \mathrm{~F}_{6} \mathrm{H}_{20}$} & IL-SmB & 351.9 & CrII-CrI & 308.6 \\
\hline & SmB-SmE & 349.1 & CrI-SmE & 347.8 \\
\hline & SmE-CrI & 336.8 & SmE-SmB & 356.5 \\
\hline & CrI-CrII & 316.3 & SmB-IL & 358.3 \\
\hline
\end{tabular}

\section{Conclusions}

The investigated (alkyl)F-alkyl(alkyl) triblock molecules have been subjected for the first time for thermal studies. Although these compounds do not possess a characteristic for liquid crystal aromatic core, but instead rigid perfluorinated fragment extended by two flexible n-alkyl segments, they were found to form thermotropic liquid crystalline phases. The performed experiments involving DSC and POM allowed us to draw the following conclusions:

- In the investigated temperature range, the studied compounds exhibit rich phase polymorphism. All the detected phases undergo the phase transitions between crystal and liquid crystalline phases, such as smectic B and smectic $\mathrm{E}$, and between smectic $\mathrm{E}$ or $\mathrm{B}$ and isotropic phase. Additionally, smectic A phase was also observed in the homolog with $n=14$.

- Two crystalline phases have been discovered in two compounds, namely those with $n=16$ and 20 . The other three homologs have only one crystalline phase.

- Two compounds with $n=12$ and 14 undergo phase transitions between vitreous and crystalline phases at temperatures between 235 and $310 \mathrm{~K}$. No vitrification process was observed in the other three homologs.

- For all the investigated compounds, it can be observed that the longer hydrocarbon chain, the higher temperature of the phase transition between smectic $\mathrm{E}$ and smectic $\mathrm{B}(\mathrm{SmE} \leftrightarrow \mathrm{SmB})$ and to the isotropic phase ( $\mathrm{SmB} \leftrightarrow$ Iso).

- No metastable phases were observed.

Open Access This article is distributed under the terms of the Creative Commons Attribution 4.0 International License (http://crea tivecommons.org/licenses/by/4.0/), which permits unrestricted use, distribution, and reproduction in any medium, provided you give appropriate credit to the original author(s) and the source, provide a link to the Creative Commons license, and indicate if changes were made.

\section{References}

1. Scott RL. The solubility of fluorocarbons. J Am Chem Soc. 1948;70:4090-3.

2. Banks RE, Smart BE, Tatlow JC. Organofluorine chemistry. Principles and commercial applications. New York: Plenum Press; 1994. 
3. Rabolt JF, Russell TP, Twieg RJ. structural studies of semifluorinated normal-alkanes. 1. Synthesis and characterization of $\mathrm{F}\left(\mathrm{CF}_{2}\right)$ ${ }_{\mathrm{n}}\left(\mathrm{CH}_{2}\right)_{\mathrm{m}} \mathrm{H}$ in the solid-state. Macromolecules. 1984;17:2786-94.

4. Broniatowski M, Dynarowicz-Łątka P. Semifluorinated alkanes: primitive surfactants of fascinating properties. Adv Colloid Interface Sci. 2008;138:63-83.

5. Krafft MP, Riess JG. Chemistry, physical chemistry, and uses of molecular fluorocarbon-hydrocarbon diblocks, triblocks, and related compounds-unique "apolar" components for self-assembled colloid and interface engineering. Chem Rev. 2009;109: 1714-92.

6. Turberg MP, Brady JE. Semifluorinated hydrocarbons: primitive surfactant molecules. J Am Chem Soc. 1988;110:7797-801.

7. Gaines GL. Surface-activity of semifluorinated alkanes$\mathrm{F}\left(\mathrm{CF}_{2}\right)_{\mathrm{m}}\left(\mathrm{CH}_{2}\right)_{\mathrm{n}} \mathrm{H}$. Langmuir. 1991;7:3054-6.

8. Mahler W, Guillon D, Skoulios A. Smectic liquid crystal from (perfluorodecyl)decane. Mol Cryst Liq Cryst Lett. 1985;2:111-9.

9. Yang DK, Wu ST. Fundamentals of liquid crystal devices. New York: Wiley; 2006.

10. Russell TP, Rabolt JF, Twieg RJ, Siemens RL, Farmer BL. Structural characterization of semifluorinated n-alkanes. 2. Solidsolid transition behavior. Macromolecules. 1986;19:1135-43.
11. Fujiwara M, Satoh K, Mita S. Liquid crystalline formation of semifluorinated n-alkanes $\mathrm{F}_{\mathrm{n}} \mathrm{H}_{\mathrm{m}}$; Molecular dynamics simulation study using atomistic model. Mol Cryst Liq Cyst. 2005;441: 307-17.

12. Wang J, Ober CK. Solid state crystalline and liquid crystalline structure of semifluorinated 1-bromoalkane compounds. Liq Cryst. 1999;26:637-48.

13. Krafft MP. Strasbourg's SOFFT team—soft functional systems self-assembled from perfluoroalkylated molecular components. J Fluorine Chem. 2012;134:90-102.

14. Migdał-Mikuli A, Szostak E, Bernard P. Thermal analysis, phase transitions and molecular reorientations in $\left[\mathrm{Sr}\left(\mathrm{OS}\left(\mathrm{CH}_{3}\right)_{2}\right)_{6}\right](-$ $\left.\mathrm{ClO}_{4}\right)_{2}$. J Therm Anal Calorim. 2014;115:443-9.

15. Jasiurkowska-Delaporte M, Juszyńska E, Kołek Ł, Krawczyk J, Massalska-Arodź M, Osiecka N, Rozwadowski T. Signatures of glass transition in partially ordered phases. Liq Cryst. 2013;40: 1436-42.

16. Goodby JW, Pindak R. Characterization of the hexatic B and crystal B phases by optical microscopy. Mol Cryst Liq Cryst. 1981;75:233-47. 